\title{
Aoristo)))))
}

International Journal of Phenomenology, Hermeneutics and Metaphysics

\section{Itinerário para a compreensão do texto Que é metafísica? de Martin Heidegger}

\author{
Itinerary for an understanding Martin Heidegger's What is \\ metaphysics?
}

\author{
Prof. Dr. Affonso Henrique Vieira da Costa \\ Universidade Federal Rural do Rio de Janeiro - UFRRJ'
}

\section{RESUMO}

O trabalho ora proposto, desde a leitura do texto Que é metafísica? pretende ser um itinerário para a compreensão do que o filósofo Martin Heidegger compreende por Metafísica. Trata-se, portanto, de um encaminhamento que, ao invés de responder a pergunta, pretende, bem ao contrário, encaminhá-la, de maneira a possibilitar ao leitor uma experiência com o seu sentido mais próprio.

\section{PALAVRAS-CHAVE}

Metafísica; Ente; Ser; Nada

\section{ABSTRACT}

The work we proposed, from an interpretation of Martin Heidegger's What is metaphysics? shows itself ideally as an itinerary for understanding what the philosopher thinks by the term Metaphysics. So, it is a referral that, instead of answering the question, on the contrary wants to consider it, in order to enable the reader to experience metaphysics in its own sense.

\section{KEYWORDS}

Metaphysics; Being; Being; Nothingness

\footnotetext{
${ }^{1}$ E-mail: affonso.henrique@uol.com.br
} 


\section{Aoristo)))))}

International Journal of Phenomenology, Hermeneutics and Metaphysics

Abrir em si feridas de questionamento, na terminologia de Heidegger, se chama: colocar a questão. Colocar a questão significa: trabalhar um problema de tal maneira que ele se torne insuportavelmente pesado para você, ao ponto de se transformar numa questão de sua vida.

(Hermógenes Harada)

M. Heidegger, em sua preleção Que é metafísica?, (HEIDEGGER, 1996) colocanos, desde o início, na condição de equilibristas, pois, lendo-o seriamente, com a radicalidade que o texto exige, encontramo-nos suspensos, naquele estágio em que não sentimos mais as determinações impostas pelos entes, mas, simplesmente, no seio do nada. Trata-se aí da experiência fundamental em que o ser-aí (Dasein) se revela para si próprio.

A exigência de participação na experiência é imposta ao leitor desde o início, quando é dito que não se tratará de falar sobre a metafísica, mas de construir uma questão, um caminho, a partir do qual isso que é a metafísica se revele, se mostre desde o seu âmago, por dentro dela mesma.

Mas o que significa encaminhar uma questão metafísica? Nesse encaminhamento encontra-se todo o método heideggeriano, a saber: dar à questão a melhor possibilidade de se apresentar em si mesma, conforme nos ensina o primeiro parágrafo do texto. Diante disso, procura construir o seu trabalho a partir de três etapas: 1) O desenvolvimento de uma questão metafísica, 2) A elaboração da questão e 3) A resposta à questão. O problema fica posto já no modo de seu desenvolvimento. O modo como a questão se põe é tudo. Ou quase tudo. Diz-se: toda questão bem colocada já traz consigo a sua resposta.

O filósofo, de antemão, manda um recado: “Considerada sob o ponto de vista do são entendimento humano, é a filosofia, nas palavras de Hegel, o 'mundo às avessas'". (HEIDEGGER, 1996, p. 51) O que isso significa? Simplesmente que, para acompanhar a preleção, faz-se necessário um abandono ao que aí vai se formando, aparecendo. Abandono aí quer dizer deixar-se ser tomado pelas questões, manter-se junto a elas, de maneira que aflorem e façam eco. O que vai aparecendo é bastante diferente daquilo que tomávamos como certo. Somos lançados numa estranheza com relação a tudo o que é e há. O manifestar-se do real revela, de alguma maneira, aquilo que disse Hegel, a saber, o mundo às avessas. Nesse sentido, a filosofia é a coragem de poder aí se instalar, ou seja, de, em uma determinada distância, que se faz desde o estranhamento, poder suportar uma questão essencial. E a questão que está em curso é, segundo o autor, metafísica. Por isso, a advertência: “De acordo com o são entendimento humano...". Talvez seja necessária uma dose de insanidade para acompanhar a questão. Estaríamos dispostos a isso?

Das muitas regiões desde as quais uma questão desta estirpe poderia ser construída, Heidegger vai desenvolvê-la a partir daquela a que pertence a atividade científica. E qual o porquê? É que, em nossa época histórica, tudo aquilo que é 


\section{Aoristo)))))}

International Journal of Phenomenology, Hermeneutics and Metaphysics

tomado como verdadeiro só é corroborado pela ciência. Se não provém dela, não é aceito no tribunal da razão, o mesmo que determina o que é e o que não é são.

Diante disso, pode-se dizer que construir tal questão é bastante difícil. Mais difícil ainda é conquistá-la, tê-la diante de nosso ser-aí, Dasein. Por isso, faz parte deste processo, diferentemente de se falar sobre a metafísica, que venhamos a participar dela tomando-a desde uma dupla característica prévia, conforme nos ensina o pensador: "A questão metafísica abarca a totalidade da metafísica e a existência de quem interroga." (HEIDEGGER, 1996, p. 51)

Está em questão o todo da realidade, sua articulação em uma unidade de sentido e o modo de ser daquele que, ao pôr a questão, põe-se também em questão. Toda dificuldade, portanto, encontra-se ligada ao fato de que se precisa encontrar uma disposição para a escuta da questão, o que exige uma abertura de nosso próprio modo de ser para que, de algum modo, presencie o dar-se disso que se denomina de totalidade.

No entanto, conforme dissemos, Heidegger parte da atividade científica. E, ao que parece, isto não é à toa. Encontramo-nos aqui, conforme nos revela Husserl, no âmago da chamada crise das ciências europeias - a crise de sua fundamentação, muito embora o que se experimente de imediato é uma alegria incomensurável com o seu pleno desenvolvimento nessa época histórica.

Diante disso, o filósofo se afunda no problema com a seguinte pergunta: "O que acontece de essencial nas raízes de nossa existência na medida em que a ciência se tornou nossa paixão?." (HEIDEGGER, 1996, p. 51)

Paixão é páthos, afecção. Trata-se, então, do fato decisivo que é a determinação que a ciência exerce sobre o Dasein. Ser determinado por ela significa: Toda a esfera de nossa existência é atravessada, quer queiramos ou não, pelo sentido que rege a atividade científica. Agimos, mesmo que inadvertidamente, na sua correspondência. Tanto é assim que muitas das vezes só acreditamos em certas coisas se elas já aparecem com o crivo da verdade científica.

O mundo objetivo da ciência transformou-se em nosso mundo. Vemos tudo através desse olhar que tudo transforma em objeto. Acreditamos que, assim, controlamos a realidade em sua objetividade, nós, sujeitos do conhecimento. Encarando tudo dessa maneira, abdicamos de outros modos a partir dos quais isso que é o real encontra-se na possibilidade de se revelar.

De maneira bastante simples, como se dá essa atividade científica? Há previamente um sujeito, que transforma o ente em um objeto de investigação, debruça-se sobre ele, fazendo-o se mostrar naquilo que ele mesmo é. Foi assim, por exemplo, que Robert Hooke (em meados do séc. XVII), ao analisar uma célula de cortiça, pôde dizer que ela era constituída de três partes: membrana plasmática, citoplasma e núcleo. Toda ciência, com isso, parte já dessa separação entre sujeito e objeto. Ela, aliás, precisa disso para ser ciência. Ela procura, com essa atitude, aproximar-se cada vez mais da verdade de seus objetos. O discurso de Heidegger - e isso precisa ficar claro - não é contra a ciência, mas se impõe na situação precária em que a ciência dispõe da realidade, a saber, quer dar a ela a primeira e a última 


\section{Aoristo)))))}

\section{International Journal of Phenomenology, Hermeneutics and Metaphysics}

palavra, eliminando, de certa maneira, todo discurso diferente do seu e que também se propõe a revelar isso que é o real.

\section{2}

O que o filósofo vai fazer, no início de sua preleção, é uma fenomenologia da atividade científica, procurando apresentá-la em seu aparecer. Com isso, a ciência, no modo como ela aí se dispõe, articulada à atividade propriamente humana, mostra-se em uma referência ao ente e, para além dele, nada. Essa atividade revela ainda todo um comportamento que se deixa determinar pelo ente em tudo o que há e é e, para além dele, nada. No fazer ciência, um ente especialíssimo - o homem - emerge dessa atividade e irrompe em meio à totalidade do ente, determinado por ele e, para além dele, nada.

No desdobramento de sua preleção, Heidegger traz consigo essas três dimensões - referência, comportamento e irrupção -, pois, através delas, isso que é a atividade científica mostra-se em sua plenitude.

No entanto, justamente nesse seu aparecer, essa atividade vai também revelar o seu fundo, a sua proveniência. Em tudo o que ela faz ou deixa de fazer, de maneira inadvertida, ecoa esse nada a partir da unidade das três dimensões acima referidas. Ao escutar o que aí se oculta, Heidegger, então, pergunta de maneira decisiva: “O que acontece com esse nada"? (HEIDEGGER, 1996, p. 53) De modo mais contundente, mostrando que este não é um fato qualquer, corriqueiro, mas decisivo em nossa existência, pergunta novamente: "É por acaso que falamos assim?" (HEIDEGGER, 1996, p. 53)

A linguagem é reveladora da situação. Ela proporciona uma ausculta que permite ir ao encontro do dito em seu dizer e que causa estranhamento. Por isso, tomado pelo que é essencial, revelado nesse estranhamento, o pensador leva a pergunta a sério deixando-se tomar pelo seu eco: O que acontece com esse nada?

O nada, então, é-nos apresentado como questão. Essa questão precisa ser elaborada. Na sua elaboração, conforme nos diz Heidegger, é necessário que percebamos seu caminho rumo a uma resposta ou então que ela se mostre como impossível de ser encontrada. Como toda fenomenologia, está em jogo aí a possibilidade de ser e de não ser da questão. Encontramo-nos num balanço em que não sabemos ao certo para onde seremos enviados. Estamos correndo atrás da questão, mas pode acontecer que, de repente, de maneira extraordinária, sejamos arrastados por ela.

O balanço exposto acima não é qualquer coisa. Ele emerge do fundo que sustenta a questão e que não se acomoda com o dado, o pronto e o acabado, mas, bem ao contrário, lança-se no cerne de sua possibilidade. Somente nesse passo é que a filosofia se faz, quando, em aporia, ainda assim encontra forças para saltar para dentro do que se revela como sendo o essencial.

O nada é posto em questão. Pergunta-se: Que é o nada? Esta pergunta é paradoxal. Poderia ela ser feita? Posso mesmo perguntar pelo ser de algo que não é 


\section{Aoristo)))))}

\section{International Journal of Phenomenology, Hermeneutics and Metaphysics}

ser nenhum? Como responder que o nada é... isso ou aquilo? O nada não é... nada! A pergunta, portanto, nem poderia ser feita. Ela trai a si mesma. Ela contradiz o princípio de não contradição.

3

Todo o transcurso da segunda parte - "A elaboração da questão" -, procura ir aos limites a partir dos quais a lógica se impõe como uma lei que paira acima de todo o entendimento. No entanto, para que a elaboração da questão siga o seu caminho, esses limites terão que ser alcançados. Em sendo alcançados, e dado que impedem a elaboração propriamente dita, eles precisam ser ultrapassados em direção a uma região mais funda, isto é, mais fundamental, que instaura isso mesmo que é a lógica. É esse salto para essa região que vai possibilitar uma investida sobre o que a lógica entende pelo não e pela negação. Não é à toa que, na investigação, quando a lógica diz que o nada não é, mas simplesmente significa a negação da totalidade do ente, o filósofo vai se perguntar: "O não e a negação são mais originários que o nada, ou o que se passa é exatamente o contrário: $O$ nada é mais originário que o não e a negação?" (HEIDEGGER, 1996, p. 54)

Essas questões se põem na base do fato de que a lógica só compreende o nada a partir da representação. Bastaria que imaginássemos o ente em sua totalidade e, em seguida, pudéssemos negá-lo. Com isso, segundo o filósofo, teríamos o "conceito formal do nada figurado". O problema se constitui com a diferença que vai se abrir entre este "nada figurado" e o que se pode chamar de "nada autêntico".

\section{4}

Mas de que se trata quando falamos do "nada autêntico"? Trata-se de uma busca. Diz-nos Heidegger:

Primeiramente e o mais das vezes o homem somente então é capaz de buscar se antecipou a presença do que busca. Agora, porém, aquilo que se busca é o nada. Existe afinal um buscar sem aquela antecipação, um buscar ao qual pertence um puro encontrar? (HEIDEGGER, 1996, p. 54)

Este último questionamento ecoa em nosso ser. Ficamos parados pensando nessa "antecipação" e em uma disponibilidade para o "encontro".

Já vimos que a tentativa de representação do nada o tomando como a negação da totalidade do ente nos afasta desse encontro. Mas como seria possível tal experiência do nada se, de antemão, é impossível para nós o conhecimento da totalidade do ente?

Heidegger faz aqui uma diferença importante entre o conhecer a totalidade do ente e o estar (ou sentir-se) em meio ao ente em sua totalidade. Isto sim é possível, aquilo não. Embora estejamos presos (ou determinados) a algum ente, esse "em totalidade" faz-se sempre presente e de maneira inadvertida. Inadvertida, pois em alguns momentos ele se manifesta em situações importantes de nossa existência 


\section{Aoristo)))))}

\section{International Journal of Phenomenology, Hermeneutics and Metaphysics}

quando, por exemplo, encontramo-nos diante do tédio ou da presença de um ente querido. No tédio, sentimo-nos entediados não por alguma coisa, não por alguma atividade, mas tudo nos entedia. Todas as coisas encontram-se niveladas. Esse nivelamento de tudo o que é nos oprime. Afundamo-nos nele. Somos oprimidos por ele. Nele esse "em totalidade" faz eco, amarra tudo em um conjunto. Todas as coisas parecem possuir o mesmo peso: $O$ peso que pesa sobre o nosso ser.

Já na presença de um ente querido, tudo ganha uma conjuntura favorável, iluminadora, em que todos os entes aparecem na luz de um sentido. Somos aí dispostos à alegria de ser em comunhão com todas as coisas, em que essa unidade se faz presente por essa mesma presença iluminadora.

Nestes dois exemplos essa presença do todo do ente se revela. Mas o decisivo é que essa mesma presença que inunda o ser-aí o afasta da manifestação do nada. Conforme vimos, não se trata de, agora, a partir da experiência da manifestação desse "em totalidade", imprimir uma negação. Por isso, a pergunta: Onde encontramos o nada? Ou ainda: "Acontece no ser-aí do homem semelhante disposição de humor na qual ele seja levado à presença do próprio nada?" (HEIDEGGER, 1996, p. 56)

\section{5}

Heidegger, a partir da pergunta acima, expõe a disposição da angústia como sendo a disposição fundamental de nosso ser-aí, Dasein, em virtude de propiciar a manifestação do nada. Angústia aqui não é medo, ansiedade, visto que ela não é determinada por este ente e nem por aquele outro. É característica de a angústia dispor-se na total indeterminação. Eu nunca estou angustiado por isso ou por aquilo, por este ou por aquele ente. Simplesmente, conforme nos indica o filósofo, "a gente se sente assim". A gente se sente angustiado. E se nos perguntam, ainda respondemos que não é nada. E é justamente o nada que nos acossa, que nos corta a palavra, que nos corta qualquer dicção do "é".

Nesta impossibilidade de dizer o "é", neste sentir-se suspenso em meio ao nada em seu manifestar, em que o ente em sua totalidade põe-se em fuga, abre-se o estranhamento com relação à totalidade do real. Por isso até mesmo o "eu" e o "tu" tornam-se impossíveis de serem ditos. Fazemos normalmente o uso do impessoal "a gente".

Conforme dissemos no início de nossa tentativa de interpretação do texto heideggeriano, a questão metafísica abarca toda a metafísica e a existência de quem interroga. Nossa existência encontra-se comprometida com a questão e vê-se por ela arrastada, perdida em meio ao nada na fuga do todo do ente.

Isso tudo se dá, acontece, porque Heidegger, em pensando na abertura do $D a$ do Dasein, do aí do ser-aí, dispõe o humano nessa mesma abertura, possibilidade de todo encontro, isto é, "região" em que ele pode ser tocado ou tomado pelo que a ele se dirige. 


\section{Aoristo)))))}

International Journal of Phenomenology, Hermeneutics and Metaphysics

O modo de ser do homem - ser-aí, Dasein -, com isso, é sempre afeito aos afetos, está sempre em um páthos, em uma disposição de humor. Ele é sempre humorado, afetado, trespassado por tudo que vem ao seu encontro. Por isso mesmo o filósofo pode afirmar que

[...] o que assim chamamos de 'sentimentos' não é um fenômeno secundário de nosso comportamento pensante e volitivo, nem um simples impulso causador dele nem um estado atual com o qual nos temos que haver de uma ou outra maneira. (HEIDEGGER, 1996, p. 56)

A questão que agora se impõe, a partir da revelação originária do nada desde a experiência da angústia que acossa o ser-aí e o coloca suspenso em meio à fuga de todo o ente, é a seguinte: "O que acontece com esse nada?" Com ela introduzimo-nos na terceira parte de seu trabalho.

\section{6}

Dois pontos nos chamam a atenção logo no primeiro parágrafo da terceira parte do texto de Heidegger "A resposta à questão": 1) A necessidade de mantermos longe de nós a determinação do nada que não se desenvolveu desde a experiência originária que propiciou sua investigação e 2) A necessidade de perseguirmos uma transformação em nosso ser-aí desde a manifestação originária do nada. Esses dois pontos são essenciais, pois eles pretendem explorar de maneira cada vez mais acentuada o salto proposto na segunda parte do texto quando o filósofo diz: "Que tenha sido este o momento derradeiro em que as objeções do entendimento retiveram nossa busca que somente pode ser legitimada por uma experiência fundamental do nada". (HEIDEGGER, 1996, p. 55)

Encontramo-nos no âmbito dessa experiência, afundados nela. É uma experiência fundamental, porque vai ao fundo. Conforme disse certa vez Nietzsche, quem muito vai ao fundo, afunda. Aqueles dois pontos são uma exigência que vem do fundo e não de um entendimento prévio que quer controlar a questão. Precisamos nos deixar conduzir pelo que a experiência abre. Trata-se de uma exigência da questão metafísica, de uma exigência de transcendência, pois é uma questão que vai para além (trans, meta) do ente em sua totalidade.

A resposta à questão, neste caso, não é propriamente uma resposta, mas um convite para que nela entremos e a habitemos, que fiquemos na sua proximidade, de tal maneira que, a partir mesmo da experiência da angústia, o nada se revele e, com ele, o ente em sua totalidade em fuga. O pensamento do filósofo aí, neste ponto, vai tentar ir ao encontro desse "com". O deparar-se "juntamente com" o ente em sua totalidade revela-nos que o nada não o destrói e nem se encontra ao seu lado, como se fossem duas coisas paralelas. $\mathrm{O}$ nada e o ente aparecem em uma unidade. $\mathrm{O}$ ente, na experiência da angústia, conforme nos apresenta Heidegger, torna-se caduco, isto é, ele perde o todo de seu sentido, ele não diz mais o que o real é ou o que se pensava que ele fosse. O fundo desde o qual ele se erguia desapareceu e, agora, esse desaparecimento se impõe como o nada do ente, isto é: o ente aparece agora como 


\section{Aoristo)))))}

\section{International Journal of Phenomenology, Hermeneutics and Metaphysics}

nunca antes fora visto, entre toda a sua possibilidade de ser e de não ser. A angústia, na sua impotência, não destrói o ente, mas passa a vê-lo desde seu nada. O nada aqui jamais é confundido com a negação do ente, pois a experiência da angústia dispõe o ser-aí na indisponibilidade de qualquer representação. A negação aí seria tardia, visto que antes de ela mesma se dar, o nada já tudo nadificou. Ele mesmo, conforme indica Heidegger, já nos visitou.

Por isso, esse "espaço" de pensamento não pode ser habitado pela lógica, pois ela mesma se detém diante daquilo que é o mais originário - o fundador mesmo das regras do entendimento. A experiência proposta pelo filósofo vai além daquela em que se insere a lógica e, por isso mesmo, ele precisa saltar por cima dela para atingir novas esferas.

\section{7}

Porém, neste saltar do salto que nos conduz ao mais originário - Ursprung -, somos conduzidos ao fundo, ao fundamento de todo o real. O salto arrasta o ser-aí para diante de si, na possibilidade de apropriação de si. Por isso mesmo, e não à toa, Heidegger pergunta: "Ele [o ser-aí] não precisa ser empurrado de antemão para o interior do aí, cujo acontecimento se torna manifesto para ele como jogado?" (HEIDEGGER, 2014, p. 310)

Trata-se de pensar o aí, o aberto, como a "região" a partir da qual isso que é o real, em toda sua possibilidade de ser e de não ser, se dá. Porém, o ser-aí é empurrado, arrastado e, nesse aberto, vê-se jogado, diante de um fundo sem fundo Abgrund -, suspenso dentro do nada.

A nadificação do nada, que se põe em curso a partir da experiência da angústia, remete ao ente como o inteiramente outro, como o estranho à medida que o rejeita. É uma experiência que toma o ser-aí colocando-o nessa remissão que rejeita. Isso que ele experimenta é o ente em sua totalidade em fuga, a retração de seu sentido.

Justamente porque nessa disposição fundamental da angústia o ser-aí pode perguntar originariamente pelo que é, Heidegger vai afirmar que "ser-aí quer dizer: estar suspenso dentro do nada". (HEIDEGGER, 1996, p. 58)

Com isso, parece-nos que a resposta à questão é propriamente um deixar-se por ela ser tomado, um entrar em experiência, de maneira que no nadificar do nada isso que é o ente enquanto tal se revele para o ser-aí. "O nada não é um conceito oposto ao ente, mas pertence originariamente à essência mesma (do ser). No ser do ente acontece o nadificar do nada". (HEIDEGGER, 1996, p. 59)

Encontrar-se consigo mesmo no aberto de seu aí é o que o filósofo chama de transcendência, isto é, a experiência que põe o ser-aí para além do ente, suspenso no meio do nada.

Se o ser-aí, nas raízes de sua essência, não exercesse o ato de transcender, e isto expressamos agora dizendo: se o ser-aí não estivesse suspenso previamente dentro do nada, ele jamais poderia entrar em 


\section{Aoristo)))))}

International Journal of Phenomenology, Hermeneutics and Metaphysics

relação com o ente e, portanto, também não consigo mesmo (HEIDEGGER, 1996, p. 58)

Então, toda experiência metafísica é reveladora do lugar em que o homem sempre já esteve, sempre já está? Então todo caminho é percorrido para se chegar onde sempre estamos? Parece ser por isso mesmo que Heidegger cita as Confissões (livro X, cap. 16, de Santo Agostinho) no $\$ 9$ de Ser e tempo: “Então, que há de mais próximo de mim do que eu mesmo? Decerto, eu trabalho aqui, trabalho em mim mesmo, transformei-me numa terra de dificuldades e de suor copioso". (HEIDEGGER, 2006, p. 87) Essa passagem é exposta pelo filósofo para explicitar que o que está onticamente mais próximo de mim, ontologicamente está mais distante. O modo como costumeiramente eu compreendo o mundo e o mundo me compreende é o que está mais próximo de mim. Mais distante é a possibilidade de ir ao encontro do fundo a partir do qual essa mesma compreensão se funda. Diante disso, há que se pensar de maneira ainda mais aguda o que o filósofo expõe quando diz que "sem a originária revelação do nada não há ser-si-mesmo, nem liberdade". (HEIDEGGER, 1996, p. 58)

\section{8}

Ser-si-mesmo não é nenhum encontrar-se com sua subjetividade; e liberdade não é ver-se livre de algum problema. Só se chega a si mesmo e só se é livre quando, na suspensão do ser-aí no seio do ente, há uma despedida das determinações, isto é, transcende-se o ente em sua totalidade e dispõe-se ao fazer-se de mundo. Disposição e transcendência abrem o estar lançado (jogado) do ser-aí para si mesmo, de maneira que ele vê que nada o subjaz, que o seu si mesmo é o que se compõe desde o acontecimento do dar-se de ser e nada na disposição de humor da angústia, a partir de um perceber-se por ela apropriado e em correspondendo a ela. Porém, e isso é decisivo, à medida que a corresponde, apropria-se de si, de seu aí como lugar-tenente do nada.

\section{9}

Uma das objeções importantes levantadas por Heidegger, no que tange à disposição de humor da angústia, é a seguinte: Não devemos nela sempre pairar para podermos estar em relação com o ente e existir? A pergunta, por si mesma, já carrega consigo os seus problemas. Estando ou não nessa disposição, já estamos sempre nos relacionando com os entes. E já estamos porque desde sempre o ser-aí habita, mesmo que sem saber disso, o aí em que o ser mesmo se dá. O que a angústia, enquanto disposição fundamental, faz, é devolver essa situação ao ser-aí, fazer com que ele se veja (seja) desde o aberto que ele mesmo é. Essa disposição é rara, assim como é raro que o ser-aí perceba que o nada é o mais das vezes dissimulado em sua originariedade. Essa dissimulação acontece porque o ser-aí encontra-se sempre ligado - em uma proximidade extrema - a esse ou àquele ente. Perdido junto ao ente, ele põe em fuga o próprio nada. Ouçamos o que Heidegger fala: 


\section{Aoristo)))))}

\section{International Journal of Phenomenology, Hermeneutics and Metaphysics}

Quanto mais nos voltamos para o ente em nossas ocupações, tanto menos nós o deixamos enquanto tal, e tanto mais nos afastamos do nada. E tanto mais seguramente nos jogamos na pública superfície do ser-aí". (HEIDEGGER, 1996, p. 59)

Quando em Ser e tempo, no início do §9, Heidegger escreve que "O ente que temos a tarefa de analisar somos nós mesmos. O ser deste ente é sempre e cada vez meu. Em seu ser, isto é, sendo, este ente se relaciona com o seu ser", (HEIDEGGER, 2006, p. 85) e, mais adiante: "Ser é o que neste ente está sempre em jogo", (HEIDEGGER, 2006, p. 86.) o filósofo procura justamente aquilo que está para além da superfície pública do ser-aí. Isto é: aquilo que também a funda enquanto superfície pública em que ele está inserido.

Dissimulação significa: Quanto mais nós nos deixamos determinar pelos entes, mais voltamos às costas para o lugar em que desde sempre estamos.

A disposição de humor da angústia permite que nos voltemos para o lugar em que desde sempre habitamos e porque o habitamos sempre nos relacionamos com tudo aquilo que é em toda a sua possibilidade de não ser.

Uma das dissimulações mais frequentes, segundo o filósofo, dá-se quando do uso da negação, quando se ainda crê na pura representação dos entes e em sua posterior negação pelo intelecto. Acredita-se, com isso, que o não está fundado na negação e que o nada simplesmente não é. Conforme foi visto, é somente a partir da experiência do nada - fundadora do entendimento -, que surge o não e a negação. Para que haja negação, isso que é o ente precisa ser apresentado desde sua possibilidade de não ser.

O 'não' não surge pela negação, mas a negação se funda no 'não' que, por sua vez, se origina do nadificar do nada. Mas a negação é também apenas um modo de uma revelação nadificadora, isto quer dizer, previamente fundado no nadificar do nada". (HEIDEGGER, 1996, p. 59)

A “Resposta à questão” é também uma posição diante da lógica. É, na verdade, um caminhar por dentro da névoa do entendimento que nos impede de ver o fenômeno em seu dar-se, na sua dimensão originária, pois o mundo da lógica se acerca do dado, estabelecendo regras sobre o que já está posto, enquanto o pensamento, como aquele que funda, dispõe-se ao dar-se, ao que se impõe no vigor do que é: é um pensamento instaurador.

É na busca da instauração, do é de todas as coisas, que se encontra o filósofo. Neste sentido, a experiência do nada não é nem positiva nem negativa, mas transitiva, transformadora, pois nos investe com o aceno do ente em seu processo de desdobramento na tensão com o nada, na possibilidade de não ser de tudo o que é. Por isso, Heidegger vai afirmar que “a ideia da 'lógica' mesma se dissolve no redemoinho de uma interrogação mais originária" (HEIDEGGER, 1996, p. 60) E a 


\section{Aoristo)))))}

International Journal of Phenomenology, Hermeneutics and Metaphysics

interrogação mais originária surge no estar-lançado do ser-aí, no aberto de seu ser, onde não há um domínio sobre as questões, mas, bem ao contrário, elas é que dominam o ser-aí, conduzindo-o por caminhos imprevistos. Por isso mesmo, chamando a atenção para a dificuldade disso que é estar (ver-se) nesse lançamento, Heidegger diz que

Mais abissal que a pura conveniência da negação pensante é a dureza da contra-atividade e a agudeza da execração. Mais responsável é a dor da frustração e a inclemência do proibir. Mais importuna é a aspereza da privação. (HEIDEGGER, 1996, p. 60)

No âmbito da abissalidade da experiência, em que há apenas o balanço do jogado, do lançado sem eira e nem beira, o ser-aí audaz, em suportando a nadificação, navega no mar da angústia sem a reivindicação de um fundo, de um fundamento fora da própria experiência. Diferentemente dessa experiência, ou mesmo para dela fugir, segundo Gilvan Fogel, o ser-aí pode também querer "assegurar existência, pois ele não suporta o balanço do jogado, a oscilação do exposto, que salta com o abrupto rebentar, que veio de nenhum lugar e vai para nenhum lugar". (FOGEL, 1999, p. 156)

A experiência do nada da angústia abre um mundo, ou seja, o é de tudo o que há, a totalidade do ente em sua possibilidade de não ser, isto é, a presença em seu puro florescer desde... nada!

O ser-aí, por já estar nessa possibilidade de experiência, por já ser desde aí - ou desde o aí de seu ser - é, nas palavras de Heidegger, transcendência. "Metafísica é o perguntar além do ente para recuperá-lo, enquanto tal e em sua totalidade, para a compreensão". (HEIDEGGER, 1996, p. 61)

Esse perguntar para além do ente faz-se desde a estranheza que é poder vê-lo como se fosse pela vez primeira. $\mathrm{O}$ acossar dessa estranheza promove a pergunta pelo "por que". Na admiração pelo fato de que o ente seja surge "o porquê". O porquê faz aparecer o destino do ser-aí como pesquisador. Sem a abertura originária que possibilita a manifestação do ente não haveria a liberdade do "por que". Toda pergunta metafísica exige daquele que pergunta a liberdade de estar suspenso no meio do nada. Por isso Heidegger vai dizer que a metafísica não é de maneira alguma uma disciplina da filosofia, mas, bem diferente, "é o acontecimento essencial no âmbito do ser-aí. Ela é o próprio ser-aí”. (HEIDEGGER, 1996, p. 63)

\section{0}

Partimos agora do final do texto Que é metafísica? mais precisamente da seguinte afirmação do filósofo:

$\mathrm{Na}$ medida em que o homem existe, acontece, de certa maneira, o filosofar. Filosofia - o que nós assim designamos - é apenas o pôr em marcha da metafísica, na qual a filosofia toma consciência de si e conquista seus temas expressos. (HEIDEGGER, 1996, p. 63) 


\section{Aoristo)))))}

International Journal of Phenomenology, Hermeneutics and Metaphysics

Então, filosofia não é o estudo do que pensaram os pensadores? Não é também a série de disciplinas presentes em seu curso? Segundo Heidegger, o que é, pois, a filosofia? Filosofia é "o pôr em marcha da metafísica". (HEIDEGGER, 1996, p. 63) Isto quer dizer, em outras palavras: desde a experiência do nada, do nadificar do nada, a partir do qual o pensamento se desdobra ao longo da história. Os temas expressos da filosofia são conquistados a partir daí. Ela corresponde, ao longo das épocas, ao aparecer histórico. Ela não se confunde com a historiografia. A ciência histórica é posterior à manifestação da história. "O pôr em marcha da metafísica" é, em outras palavras, entrar na dinâmica de desdobramento da história, de seu aparecer, corresponder a esse desdobramento, ser de acordo com ele. Na filosofia - por isso Kant afirma que não há filosofia sem filosofar - já estamos sempre dentro da questão, sempre em questão. Não há outra maneira de se fazer filosofia, a não ser filosofando. E quando é que se filosofa? Heidegger responde: “A filosofia somente se põe em movimento por um peculiar salto da própria existência nas possibilidades fundamentais do ser-aí, em sua totalidade". (HEIDEGGER, 1996, p. 63) De outro modo: É somente indo ao fundo, afundando no abismo do ser-aí, indo ao encontro do que sempre e desde sempre se é, que a totalidade do real se manifesta em uma unidade de sentido, tornando possível que se possa fazer a pergunta radical que, segundo o filósofo, atravessa toda a história da filosofia: "Por que há simplesmente o ente e não antes o nada?".

\section{1}

É estranho, mas a "Resposta à questão" termina com essa pergunta. Se abrirmos o Posfácio de 1943, veremos que ele assim se inicia: “A pergunta 'Que é metafísica?' permanece uma pergunta". (HEIDEGGER, 1996, p. 67) Toda a dificuldade do filosofar se resume em sustentar uma pergunta fundamental, viver junto a ela, deixá-la fermentar, amadurecer, dar frutos. Para isso, Heidegger nos dá uma indicação, contida no mesmo Posfácio:

Respostas essenciais são, constantemente, apenas o último passo das questões. Este passo, porém, permanece irrealizável sem a longa série dos primeiros passos e dos que seguem. A resposta essencial haure sua força sustentadora na in-sistência do perguntar. (HEIDEGGER, 1996, p. 68)

Essa insistência só se realiza, no seu sentido mais pleno, no âmbito da transcendência, onde o ser-aí conquista o seu lugar, aquele que, de alguma maneira, sempre já foi seu. Conquistar o seu lugar, habitar o aí do ser, o aberto de possibilidades, é que permite ao humano afundar na questão, ser puxado por ela a partir de uma entrega originária ao que é essencial. É no cerne dessa entrega, deixando-se conduzir pelo caminho que vai se abrindo, em meio a circunstâncias imprevistas, que os passos mesmos vão se formando, tornando a pergunta cada vez 


\section{Aoristo)))))}

International Journal of Phenomenology, Hermeneutics and Metaphysics

mais exposta, evidente, clara, autossustentável. Dizemos "autossustentável" porque ela se põe e se impõe desde si mesma. Ela surge para o ser-aí insistente. Ela, conforme dissemos, se expõe nessa insistência.

\section{CONSIDERAÇÕES FINAIS}

Essa exposição, portanto, não é o fim, mas, como nos ensina Heidegger, “o começo de uma responsabilidade". Mais ainda: "Nela o interrogar desperta mais originariamente. É também, por isso, que a questão autêntica não é suprimida pela resposta encontrada". (HEIDEGGER, 1996, p. 68)

\section{REFERÊNCIAS}

FOGEL, Gilvan. Martin Heidegger et coetera e a questão da técnica, in Da solidão perfeita. Petrópolis: Vozes, 1999.

HARADA, Hermógenes. Iniciação à filosofia. Rio de Janeiro: Daimon Editora, 2009.

HEIDEGGER, Martin. Contribuições à filosofia: Do acontecimento apropriador. Tradução de Marco Antônio Casanova. Rio de Janeiro: Via Vérita, 2014.

. Marcas do caminho. Tradução de Enio Giachini e Ernildo Stein. Petrópolis: Vozes, 2008.

. Que é metafísica?, Posfácio e Introdução, in Conferências e escritos filosóficos - Coleção "Os

pensadores - Heidegger". Tradução de Ernildo Stein. São Paulo: Nova Cultural, 1996. . Ser e tempo. Tradução de Márcia Schuback. Petrópolis: Vozes, 2006.

Submetido: 10 de janeíro de 2021

Aceito: 9 de fevereíro de 2021 